\title{
THE EFFECT OF FLOWER OCCUPANCY ON THE FORAGING OF FLOWER-VISITING INSECTS*
}

\author{
By V. J. Tepedino and F. D. Parker \\ Bee Biology \& Systematics Laboratory, Agricultural Research, \\ Science \& Education Admin., \\ USDA \\ Utah State University, UMC 53 \\ Logan, Utah

\section{INTRODUCTION}

To locate flowers, insects use a variety of visual and olfactory cues such as flower color, shape, movement and scent (Faegri and van der Pijl 1971). In addition, other insects on the flowers may also serve as cues that either attract or repel prospective foragers. First, foragers might avoid occupied inflorescences because: 1) there is a high probability that other flowers on the inflorescence have been recently exploited (Pleasants and Zimmerman 1979, Zimmerman1981); 2) of the potential loss of time and energy due to aggressive encounter with the occupant (Kikuchi 1963, Decelles and Laroca 1979); 3) the occupant might be an enemy (e.g., thomisids, phymatids, etc.). Thus, when flowers are abundant, unoccupied inflorescences may yield a greater quantity of energy and/or nutrients per unit effort. If so, the distribution of foragers across inflorescences should be regular or underdispersed, i.e., there should be more inflorescences with only one insect than expected on the assumption of a random distribution.

Existing evidence also suggests that a second hypothesis is tenable. Prospective foragers may be attracted by floral occupants because: 1) the presence of other foragers indicates that resources are available on the inflorescence; 2) the occupants themselves are sources of pollen to some foragers (Laroca and Winston 1978, Thorp and Briggs 1980). If insects are attracted to occupied inflorescences, then their distribution across inflorescences should be over-dispersed.

*Manuscript received by the editor October 20, 1981 
In this paper we use data for insects foraging on plantings of commercial sunflowers (Helianthus annuus L.) and onions (Allium cepa L.) to test these hypotheses.

An additional question of interest is whether bee species differ in their distribution across flowers. For example, Benest (1976) has suggested that honeybees (Apis mellifera L.) are more tolerant of joint foraging than are bumblebees (Bombus sp.) and Kalmus (1954) reported that honeybees tend to form clusters at artificial feeding sites. Group foraging, leading to clumped distributions on flowers has also been reported for several tropical bee species (Frankie and Baker 1974). To ascertain if the distribution of the multispecies assemblage obscured differences among the component species, we compared the distributions of the more abundant species with the balance of other foraging individuals on the inflorescences.

\section{METHODS}

Five cultivars of sunflower and 2 of onions were grown at the Greenville Farm Agricultural Research Station in North Logan, Utah. Sunflowers were planted in 5 adjacent $40 \mathrm{~m}$ rows, 1 row per cultivar. The 2 onion cultivars were planted alternately in 4 adjacent rows, 2 rows per cultivar.

Counts of floral visitors were made several times during the flowering period as 1 observer (FDP) walked along each row. A tape recorder facilitated observations. Only heads with some open flowers were censused.

The data were transcribed to number of flower heads with zero, one, two, etc. insects and then compared with values expected on the assumption of a Poisson distribution (Southwood 1978). The Poisson series describes a random distribution and is written $P_{x}(k)=$ $\mathrm{e}^{-\overline{\mathrm{x}}}\left(\overline{\mathrm{x}}^{\mathrm{k}} / \mathrm{K}\right.$ !) where $\mathrm{e}=$ base of Napierian logarithms, and $\mathrm{P}_{\mathrm{x}}$ is the expected number of flower heads with $\mathrm{k}$ insects $(\mathrm{k}=0,1,2,---)$. The parameter $\overline{\mathbf{x}}$ is estimated by the mean number of insects per flower head. For the Poisson distribution, the mean and variance are equal, and an indication of the dispersion of insects across flowers is given by the coefficient of dispersion (C.D. $=\mathrm{s}^{2} / \overline{\mathrm{x}}$ ). When C.D. is $>1.0$ the dispersion is clumped or contagious; and when $<1.0$ dispersion is regular or repulsed (Southwood 1978). The expected 
and observed distributions were tested for significance using the $x^{2}$ test (Zar 1974).

The distributions of more abundant species across sunflower heads was compared with the balance of the foraging assemblage as follows: each individual recorded was assigned to one of two mutually exclusive categories, according to whether it foraged alone or with at least one other insect (irrespective of species) on the inflorescence. A chi-square test of independence was used to compare each species represented by $>10$ individuals with the balance of the assemblage.

\section{RESULTS}

Bees were the predominant visitors to sunflowers; we recorded 15 species in 5 families (Appendix). The species were similar to that reported previously by Parker (1981) for the same study site. Onion visitors included many species of wasps and flies that did not forage on sunflowers. In contrast to sunflowers, there were more non-bee than bee visitors to onions.

For all sunflower censuses the distribution of total insects across flower heads did not differ significantly from a Poisson distribution, i.e., insects appeared to be foraging independently of other insects. The coefficients of dispersion were mostly around 1.0. There was no tendency for C.D.'s to be greater or less than 1; for 8 censuses C.D. was $>1.0$ and for 6 censuses C.D. $<1.0$. (Table 1).

Only 2 of 7 censuses of onions deviated significantly from a random distribution (Table 1). Both deviations occurred on the same day and were in the direction of under-dispersion; more heads with single visitors were recorded than expected. There was a general tendency for insects visitors to be under-dispersed on onions; in all tests C.D. > 1.0.

There was no indication that any particular species foraged other than randomly, with respect to other occupants of sunflower heads. The results of 34 comparisons of the distribution of individuals of abundant species with the balance of foragers for the single and joint foraging categories are shown in Table 2. Only one comparison yielded significant results; another closely approached significance (7/31 Peredovik, AM, Halictus ligatus, $\mathrm{P} .=0.051$ ). It is likely that these two instances were due to chance. 


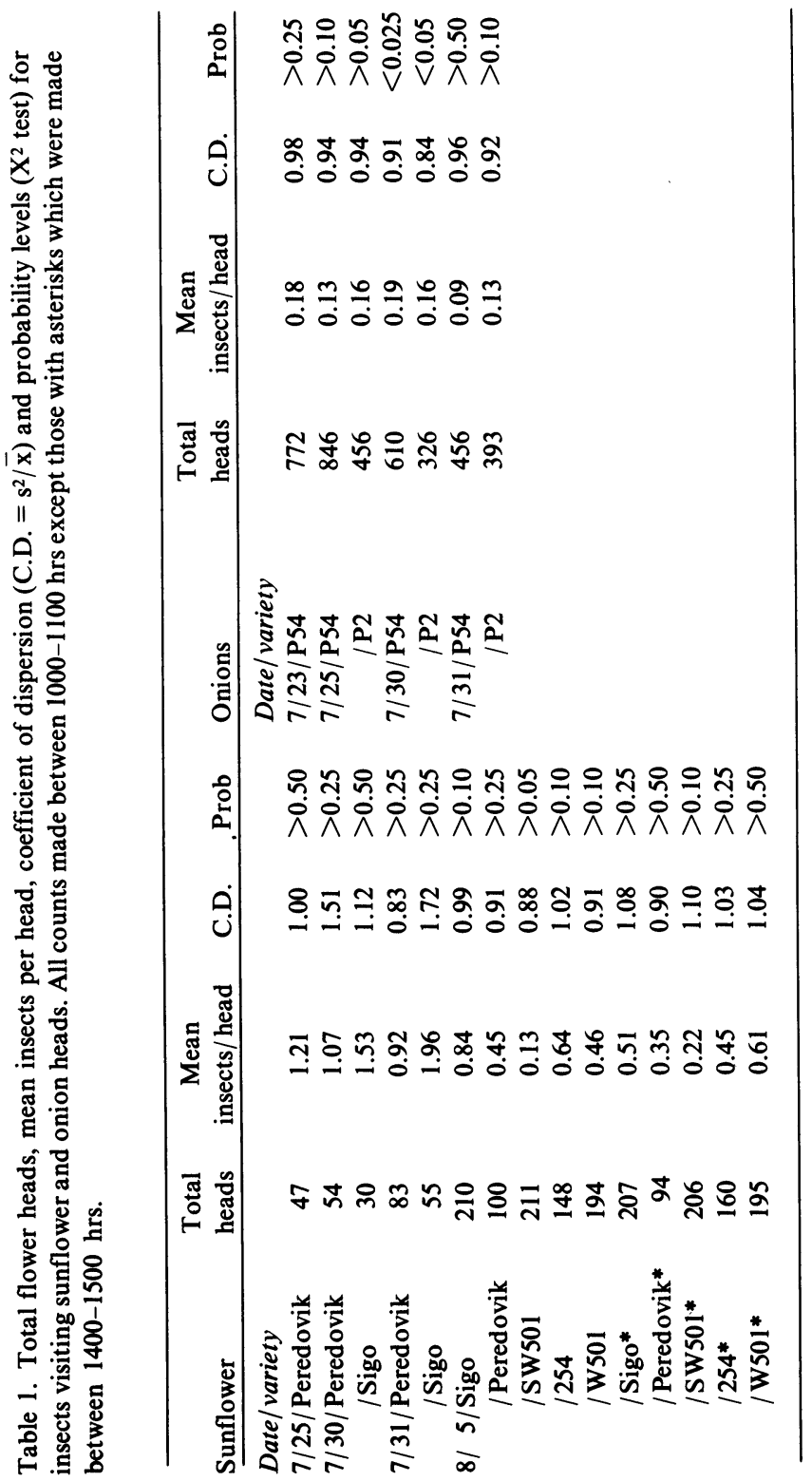




\section{Discussion}

In this study, foraging insects did not appear to react to the presence of other insects in choosing flowers. Only 2 of the censuses on onions and none of the censuses on sunflowers displayed a significant departure from a random distribution (Table 1). Sunflower foragers (Apis, Perdita, Halictus) frequently entered the flower by landing on the back of the petals or on the involucral bracts and then crawling onto the head. If occupancy by another insect were important, this would be an inefficient method of choosing a flower. In a similar study Waddington (1976) also concluded that halictid bees were foraging independently on bindweed (Convolvulus arvensis). None of the abundant species present appeared to forage other than randomly with respect to other flower occupants. This was especially surprising for honeybees which have been reported to more readily tolerate, or even form, clumped distributions (Kalmus 1954, Benest 1976). However, contagious distributions of honeybees may occur only under unusual circumstances; the data of Kalmus (1954) were gathered from a small number of feeding dishes and are quite artificial. Benest's (1976) suggestion that honeybees are more tolerant of joint foraging than bumblebees does not stand close examination. Additional study is required before such conclusions are warranted.

Instead of using the presence of insects on inflorescences as cues, some flower-visiting insects may make selections based on the number of open flowers or the amount of nectar or pollen available. Although all heads censused had some open flowers, some had more open flowers than others and insects may have been choosing those heads with more flowers irrespective of other visitors. Even if heads were equivalent in number of flowers, continuous removal of nectar and pollen by foragers would cause variation in resource availability between heads (e.g., Pleasants and Zimmerman 1979) and insects may be responsive to such variation prior to landing on a flower. For example, Thorp et al. (1975) have suggested that the fluorescent nectar (and perhaps pollen) of many species with open flowers may be used as a cue by foraging insects (see also Kevan 1976, Thorp et al. 1976); and onion nectar is intensely fluorescent (Thorp et al. 1975). Recently Heinrich (1979) has shown that bumblebee foragers reject many more nectar depleted (recently visited) white clover (Trifolium repens) heads than heads with abundant nectar. Rejec- 


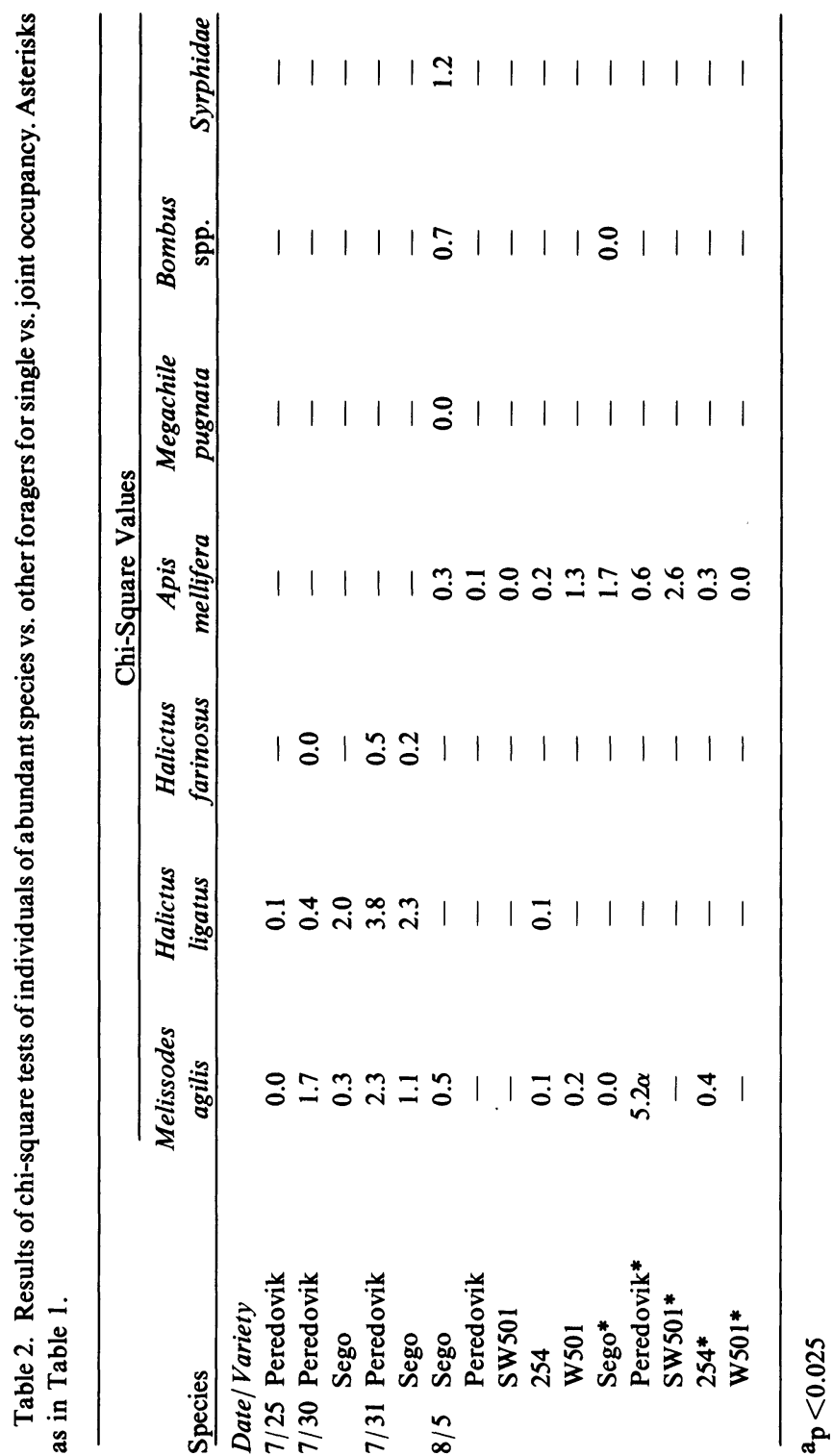


tion was accomplished without landing and the cue was probably scent of nectar (Heinrich 1979). Future field studies should explore the use of these more subtle cues by foraging insects.

\section{ACKNOWLEDGMENTS}

We thank Drs. Ivan Palmbad and Richard Rust for reviewing the manuscript.

\section{APPENDIX}

Insect taxa visiting sunflower and onion plantings.

Sunflowers

Hymenoptera: Bees-Andrenidae [Andrena helianthi Robertson, Perdita sp., Pseudopanurgus sp., Pterosarus sp.]; Anthophoridae [Melissodes agilis Cresson, Svastra obligua (Say), Triepeolus helianthi (Robertson)]; Apidae [Apis mellifera Linnaeus, Bombus spp.]; Halictidae [Agapostemon sp., Dialictus sp., Halictus farinosus Smith, Halictus ligatus Say]; Megachilidae [Megachile paralella Smith, Megachile pugnata Say].

Diptera: Syrphidae

Lepidoptera: Hesperiidae

Onions

Hymenoptera: Bees-Apidae [Bombus sp.]; Halictidae [Evylaeus sp, Halictus farinosus Smith, Halictus ligatus Say]; Megachilidae [Hoplitis fulgida (Cresson), Megachile pacifica (Panzer), Megachile sp.].

Wasps-Eumenidae [Euodynerus sp., Pterocheilus sp.]; Ichneumonidae; Sphecidae [Ammophila sp., Astata sp., Cerceris sp., Philanthus sp., Podalonia sp., Sphex sp., Tachytes sp.]

Diptera: $\quad$ Muscidae; Nemestrinidae; Sarcophagidae; Syrphidae; Tachinidae.

Lepidoptera: Hesperiidae 


\section{Literature Cited}

Benest, G.

1976. Relations interspecifiques et intraspecifiques entre butineuses de Bombus sp. et d'Apis mellifica L. Apidologie, 7:113-127.

Decelles, P. and S. Laroca

1979. Behavioral interactions among solitarily foraging bees (Hymenoptera: Apoidea). J. Kansas Entomol. Soc., 52:483-488.

Faegri, K. and L. Van Der Pijl

1971. The Principles of Pollination Ecology. 2nd Ed. Rev. London. Pergamon Press. $291 \mathrm{pp}$.

Frankie, G. W. and H. G. Baker

1974. The importance of pollinator behavior in the reproductive biology of tropical trees. An. Inst. Biol. Univ. Nal. Auton. Mexico 45 Ser. Botanica, (1):1-10.

HEINRICH, B.

1979. Resource heterogeneity and patterns of movement in foraging bumblebees. Oecologia, 40:235-245.

Kalmus, H.

1954. The clustering of honeybees at a food source. Brit. J. Anim. Behav., 2:63-71.

Kevan, P. G.

1976. Fluorescent nectar. Science, 194:341-342.

KIKUCHI, T.

1963. Studies on the coaction among insects visiting flowers. III. Dominance relationship among flower-visiting flies, bees and butterlies. Sci. Rep. Tohoku Univ. Ser. IV (Biol.), 29:1-8.

LaRoca, S. and M. L. Winston

1978. Interaction between Apis and Bombus (Hymenoptera: Apidae) on the flowers of tall thistle: honeybees gather pollen from bodies of bumblebees. J. Kansas Entomol. Soc., 51:274-275.

PARKeR, F. D.

1981. Sunflower pollination: abundance, diversity and seasonality of bees and their effect on yields. J. Apic. Res., 20:49-61.

Pleasants, J. M. and M. Zimmerman

1979. Patchiness in the dispersion of nectar resources: evidence for hot and cold spots. Oecologia, 41:283-288.

Southwood, T. R. E.

1978. Ecological Methods, 2nd Ed. Rev. London: Chapman \& Hall. 524 pp.

Thorp, R. W., D. L. Briggs, J. R. Estes, ANd E. H. Erickson

1976. Fluorescent nectar. Science, 194:341-342.

Thorp, R. W., D. L. Briggs, J. R. Estes and E. H. ERICKSON

1975. Nectar fluorescence under ultraviolet radiation. Science, 189:476-478.

ThORP. R. W. AND D. L. BRIGGS

1980. Bees collecting pollen from other bees (Hymenoptera: Apoidea). J. Kansas Entomol. Soc., 53:166-170. 
WADDINGTON, K. D.

1976. Foraging patterns of halictid bees at flowers of Convulvulus arvensis. Psyche, 83:112-119.

ZAR, J. H.

1974. Biostatistical Analysis. Englewood Cliffs, N. J.: Prentice-Hall. ZiMMERMAN, M.

1981. Patchiness in the dispersion of nectar resources: Probable causes. Oecologia, 49:154-157. 

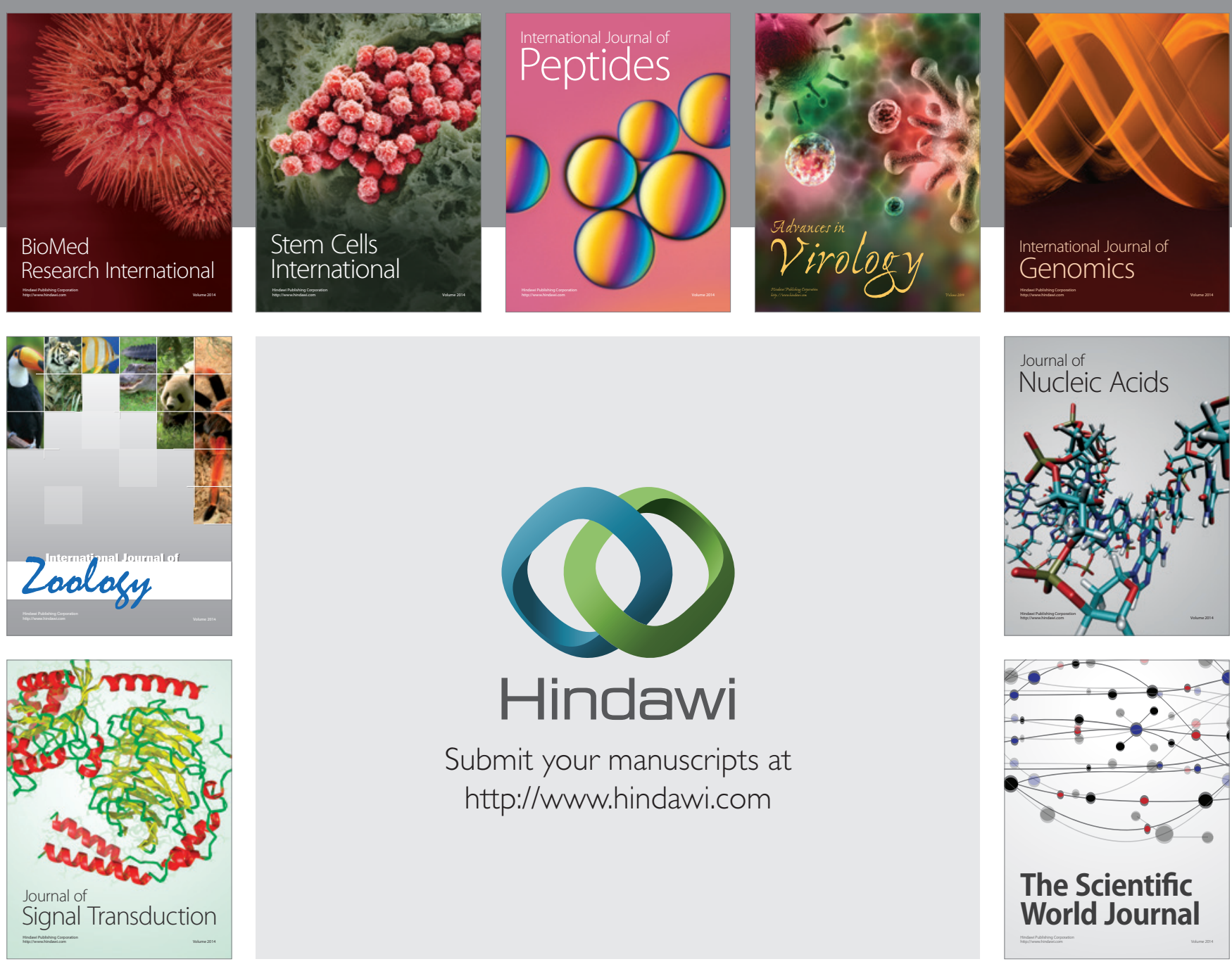

Submit your manuscripts at

http://www.hindawi.com
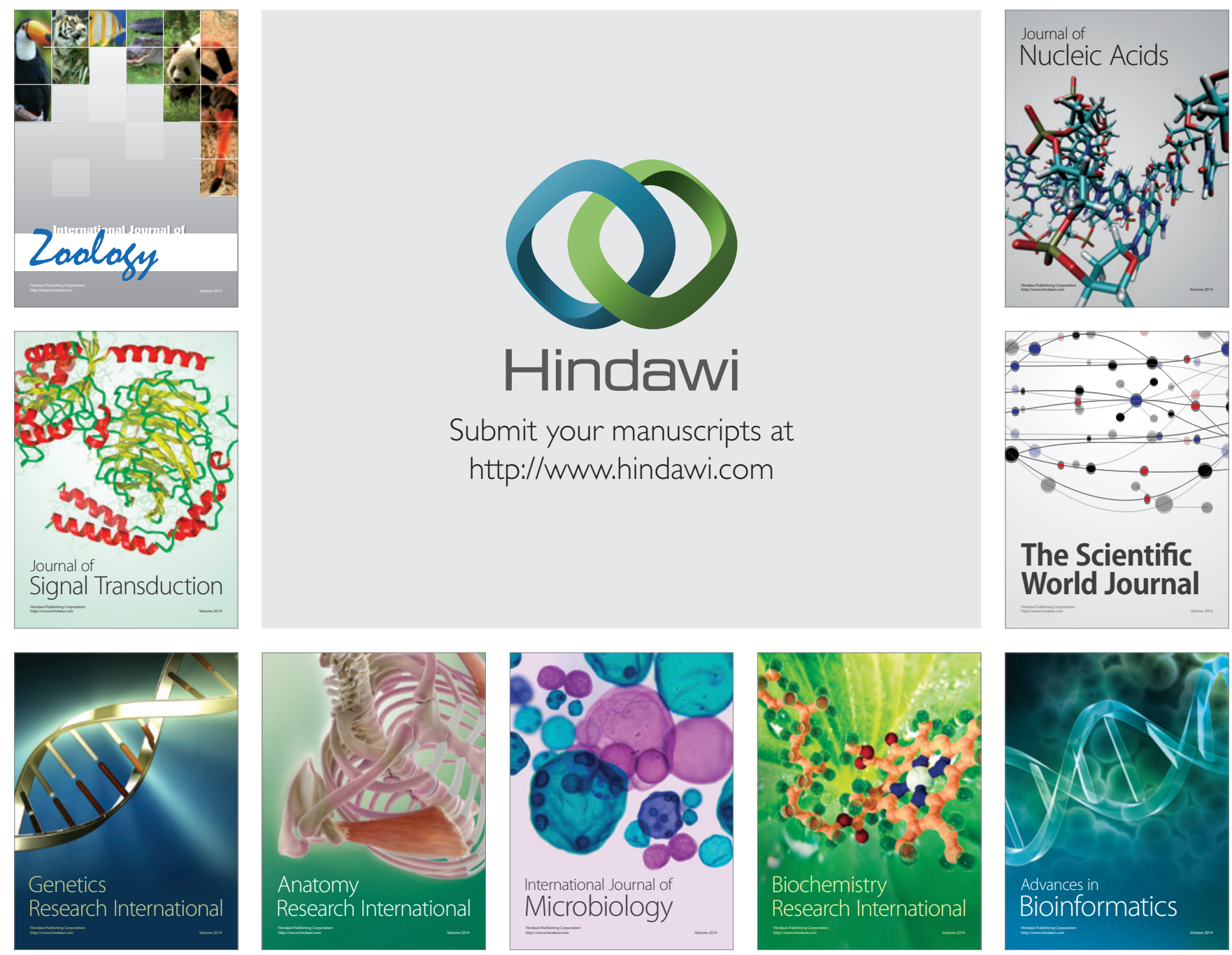

The Scientific World Journal
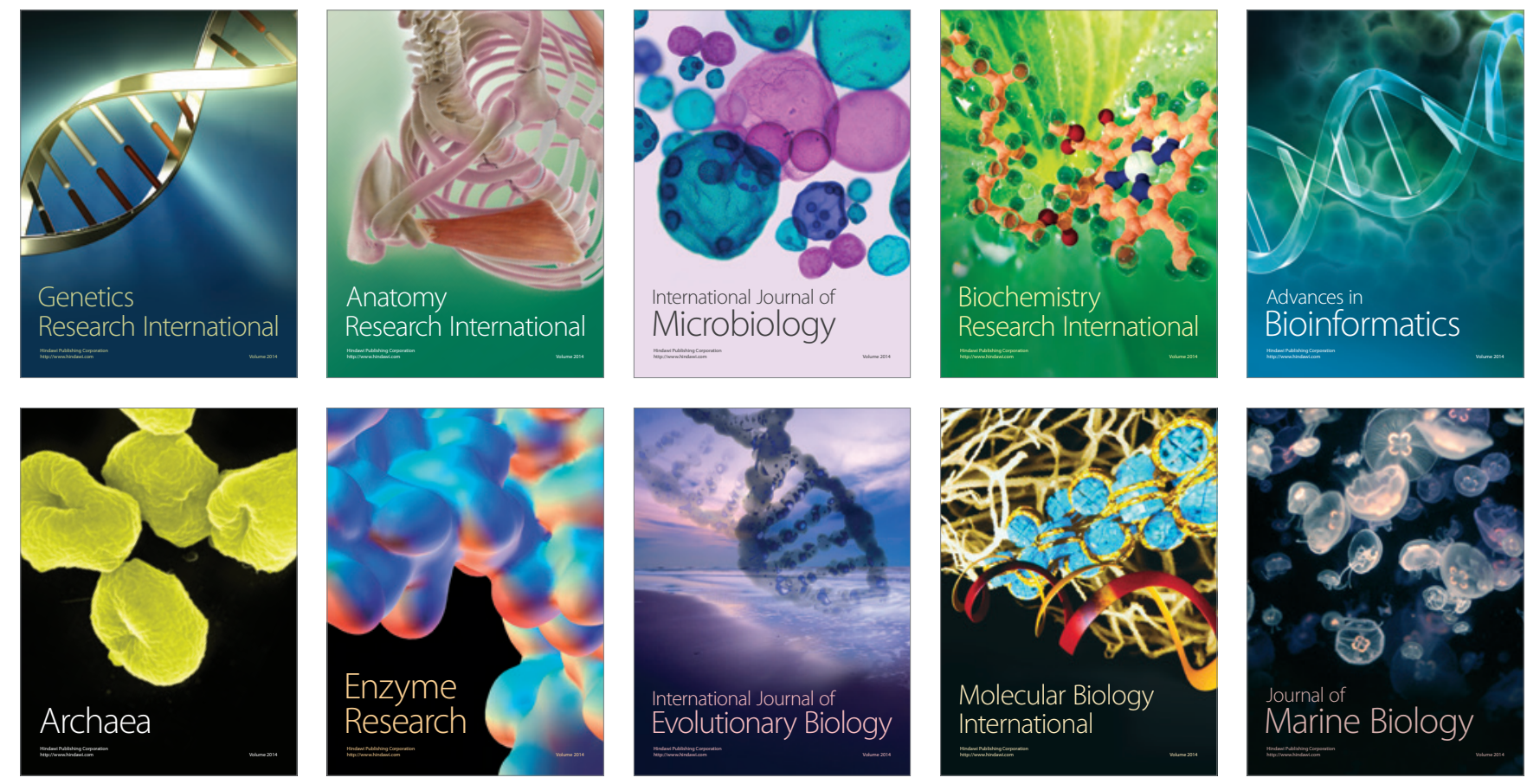